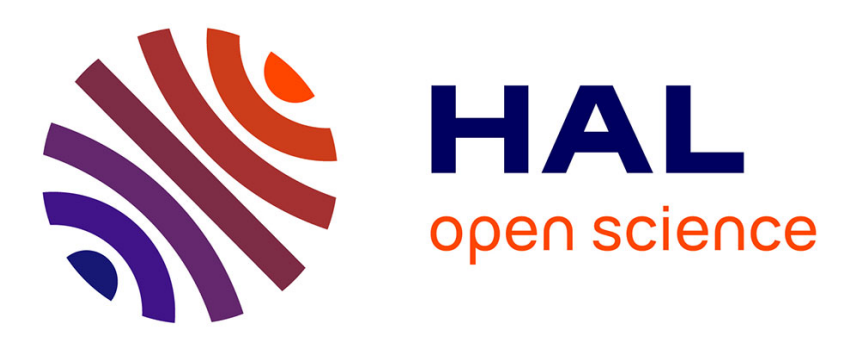

\title{
Synthesis and Structure of a Macrocyclic Dinickel Complex Incorporating a Hypercoordinated Sulfenium(II) Cation
}

Berthold Kersting

\section{- To cite this version:}

Berthold Kersting. Synthesis and Structure of a Macrocyclic Dinickel Complex Incorporating a Hypercoordinated Sulfenium(II) Cation. Journal of Inorganic and General Chemistry / Zeitschrift für anorganische und allgemeine Chemie, 2010, 636 (8), pp.1435. 10.1002/zaac.201000048 . hal-00599854

\section{HAL Id: hal-00599854 \\ https://hal.science/hal-00599854}

Submitted on 11 Jun 2011

HAL is a multi-disciplinary open access archive for the deposit and dissemination of scientific research documents, whether they are published or not. The documents may come from teaching and research institutions in France or abroad, or from public or private research centers.
L'archive ouverte pluridisciplinaire HAL, est destinée au dépôt et à la diffusion de documents scientifiques de niveau recherche, publiés ou non, émanant des établissements d'enseignement et de recherche français ou étrangers, des laboratoires publics ou privés. 


\section{Zeitschrift für Anorganische und}

Allgemeine Chemie

\section{Synthesis and Structure of a Macrocyclic Dinickel Complex Incorporating a Hypercoordinated Sulfenium(II) Cation}

\begin{tabular}{|r|l|}
\hline Journal: & Zeitschrift für Anorganische und Allgemeine Chemie \\
\hline Manuscript ID: & zaac.201000048.R1 \\
\hline $\begin{array}{r}\text { Wiley - Manuscript type: } \\
\text { Author: }\end{array}$ & Communication \\
\hline Complete List of Authors: & $\begin{array}{l}\text { Kersting, Berthold; Universitaet Leipzig, Institut fÂ■ r Anorganische } \\
\text { Chemie }\end{array}$ \\
\hline Keywords: & Macrocyclic ligands, Sulfenium Cation, Nickel, Crystal structure \\
\hline $\begin{array}{l}\text { Note: The following files were submitted by the author for peer review, but cannot be converted } \\
\text { to PDF. You must view these files (e.g. movies) online. }\end{array}$ \\
\hline $\begin{array}{l}\text { Fig1.cdx } \\
\text { Fig2.cdx }\end{array}$ \\
\hline
\end{tabular}

\section{s scholaroNE \\ Manuscript Central}




\title{
Synthesis and Structure of a Macrocyclic Dinickel Complex Incorporating a Hypercoordinated Sulfenium(II) Cation
}

Mathias Gressenbuch and Berthold Kersting*

Received ...

\begin{abstract}
The synthesis and structure of a macrocyclic dinickel complex incorporating a hypercoordinated sulfenium(II) cation are reported. The novel complex $\left[\mathrm{Ni}_{2} \mathrm{~L}^{3}(\mathrm{Cl})\right]^{2+}$ was obtained from a reaction of the per-hydroxyethylated $\mathrm{N}_{6} \mathrm{~S}_{2}$ macrocycle $\mathrm{H}_{2} \mathrm{~L}^{2}$ with $\mathrm{NiCl}_{2}\left(\mathrm{H}_{2} \mathrm{O}\right)_{6}$ in the presence of air, and isolated as its $\mathrm{ClO}_{4}$ or $\mathrm{BPh}_{4}$ salt. The structure reveals a three-coordinate sulfenium cation that is stabilized by two intramolecularly coordinating amino groups. The N-S bonds are 2.087(7) $\AA$ and 2.105(6) $\AA$ and the N-S-N bond angle is $168.2(2)^{\circ}$. The bonding is best described by a N,N-chelated sulfur(II) atom (3c-4e bond) bearing two lone pairs and a formal charge of +1 .
\end{abstract}

Keywords: Macrocyclic ligands / Sulfenium Cation / Nickel / Crystal structure

Prof. Dr. B. Kersting

Institut für Anorganische Chemie

Universität Leipzig, Johannisallee 29

D-04103 Leipzig, Germany

Tel.: +49-341-9736143

Fax.: +49-341-9736199

E-mail: b.kersting@uni-leipzig.de 
The synthesis and structural characterization of a number of hypercoordinated organoselenium and -tellurium compounds have been reported [1]. Typical examples are the chalcogenenium cations $2\left(\mathrm{RSe}^{+}\right)$and $\mathbf{3}\left(\mathrm{RTe}^{+}\right)$(Fig. 1) [2], both formally six-valence electron species, which are stabilized by two intramolecular $N^{\cdots} \mathrm{E}^{\mathrm{E}}$ interactions $(\mathrm{E}=\mathrm{Se}, \mathrm{Te})$.
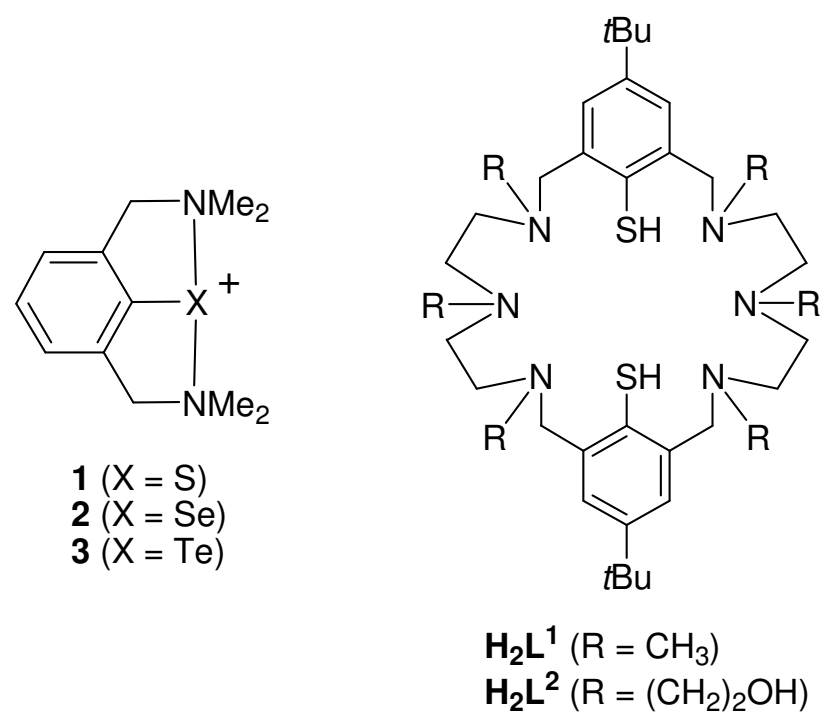

Fig. 1. Structures of compounds $\mathbf{1 - 3}, \mathrm{H}_{2} \mathrm{~L}^{1}$ and $\mathrm{H}_{2} \mathrm{~L}^{2}$.

While the chemistry of such hypercoordinate selenenium and tellurenium compounds is now fairly well-understood [3], surprisingly little is known about their corresponding sulfenium analogs $\left(\mathrm{RS}^{+}\right)$. Sulfenium cations are difficult to isolate as they are highly electrophilic and susceptible to nucleophilic attack, and only few cationic examples such as $\mathbf{1}$ have been structurally characterized to date [4]. In the course of our work on the coordination chemistry of macrocyclic amine-thiophenolate ligands $\mathrm{H}_{2} \mathrm{~L}^{1}$ and $\mathrm{H}_{2} \mathrm{~L}^{2}[5,6]$, we have now been able to isolate and structurally characterize a macrocyclic complex $\left[\mathrm{Ni}_{2} \mathrm{~L}^{3}(\mathrm{Cl})\right]^{2+}$ (Fig. 2) incorporating such a hypercoordinated sulfur species. These results are described herein.

\section{Results and Discussion}

The dark green macrocyclic complex $\left[\mathrm{Ni}_{2} \mathrm{~L}^{3}(\mathrm{Cl})\right]^{2+}$ was reproducibly obtained in ca. $80 \%$ yield by treatment of the protonated form of the per-hydroxyethylated macrocycle $\mathrm{H}_{2} \mathrm{~L}^{2}$ [7] 
with two equivalents of $\left[\mathrm{Ni}\left(\mathrm{H}_{2} \mathrm{O}\right)_{6}\right] \mathrm{Cl}_{2}$ in methanol in the presence of $\mathrm{NEt}_{3}$ and air at ambient temperature, followed by precipitation with $\mathrm{LiClO}_{4}$. This reaction is accompanied by an oxidation of the ligand $\left(\mathrm{L}^{2}\right)^{2-}$ to $\left(\mathrm{L}^{3}\right)^{-}$[8]. Previously, only isothiazoles have been isolated from air-oxidation of macrocyclic amino-thiophenolates [9].

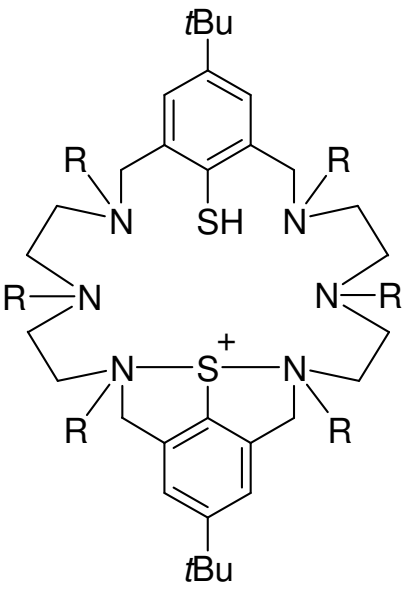

$\mathrm{HL}^{3}\left(\mathrm{R}=\left(\mathrm{CH}_{2}\right)_{2} \mathrm{OH}\right)$

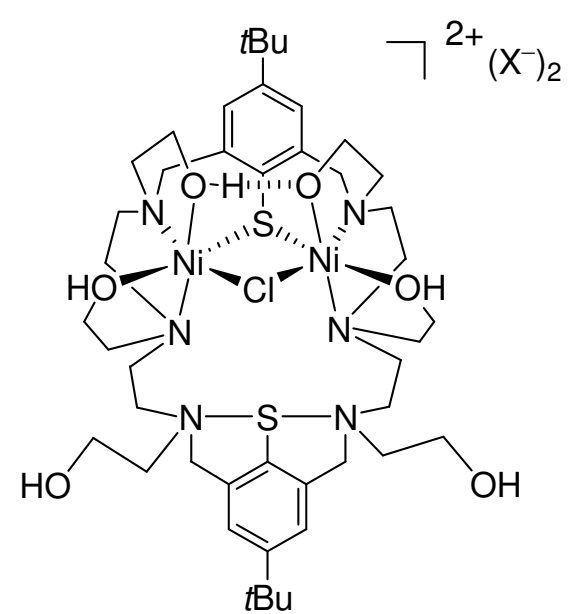

$\left[\mathrm{Ni}_{2} \mathrm{~L}^{3}(\mathrm{Cl})\right]\left[\mathrm{ClO}_{4}\right]_{2}\left(4, \mathrm{X}=\mathrm{ClO}_{4}^{-}\right)$

$\left[\mathrm{Ni}_{2} \mathrm{~L}^{3}(\mathrm{Cl})\right]\left[\mathrm{BPh}_{4}\right]_{2}\left(\mathbf{5}, \mathrm{X}=\mathrm{BPh}_{4}{ }^{-}\right)$

Fig. 2. Structures of the ligand $\mathrm{HL}^{3}$ and its $\left[\mathrm{Ni}_{2} \mathrm{~L}^{3}(\mathrm{Cl})\right]^{+}$complex in $\mathbf{4}$ and $\mathbf{5}$.

The electrospray ionization mass spectrum (ESI-MS) of a dilute acetonitrile solution of 4 exhibited a molecular ion peak with the correct isotopic distribution for $\left[\mathrm{Ni}_{2} \mathrm{~L}^{3}(\mathrm{Cl})\right]\left[\mathrm{ClO}_{4}\right]^{+}$ $(m / z=1097.31)$, and elemental analysis agreed well with the formula $\left[\mathrm{Ni}_{2} \mathrm{~L}^{3}(\mathrm{Cl})\right]\left[\mathrm{ClO}_{4}\right]_{2}$. The $\left[\mathrm{Ni}_{2} \mathrm{~L}^{3}(\mathrm{Cl})\right]^{2+}$ cation was also isolated as its tetraphenylborate salt $\mathbf{5}$.

Crystals of $5 \cdot 3 \mathrm{MeOH}$ are monoclinic, space group $P 2_{1} / c$. The asymmetric unit contains a dicationic complex (Fig. 3), two tetraphenylborate anions (one of them disordered), and three methanol solvate molecules. Charge considerations imply the presence of one deprotonated hydroxyethyl arm (assuming the presence of two $\mathrm{Ni}^{2+}$ ions, a sulfenium $\left(\mathrm{RS}^{+}\right)$cation, one thiophenolate residue, a chloride ion, two $\mathrm{BPh}_{4}{ }^{-}$anions, and the $\mathrm{CH}_{2} \mathrm{CH}_{2} \mathrm{O}^{-}$group). The latter is most likely coordinated to Ni2, as it accepts intra- (O1 $\cdots$ O6 2.469 $\AA$ ) and intermolecular hydrogen bonds (O6“' O5' $2.548 \AA$ ). Such $\mathrm{Ni}_{2}\left(\mathrm{RO}-\mathrm{H}^{\cdots} \mathrm{OR}\right)$ structures are not unusual and occur in other dinuclear nickel(II) complexes [10]. In the present structure hydrogen bonds 
are also seen between the $\mathrm{MeOH}$ solvate molecules and the hydroxyethylarms of the $\left[\mathrm{Ni}_{2} \mathrm{~L}^{3}(\mathrm{Cl})\right]^{2+}$ dication $\left(\mathrm{O} 2 \cdots \mathrm{O} 7^{\mathrm{MeOH}} 2.532 \AA\right.$, $\mathrm{O} 3 \mathrm{a} \cdots \mathrm{O}^{\mathrm{MeOH}} 3.140 \AA$, and $\mathrm{O} 4 \cdots \mathrm{O} 9^{\mathrm{MeOH}} 2.852 \AA$, not shown in Figure 3). The $\mathrm{Ni}$ atoms have a distorted octahedral $\mathrm{N}_{2} \mathrm{O}_{2} \mathrm{SCl}$ coordination environment with normal bond lengths. The Ni'Ni distance is at $3.397 \AA$.

The sulfenium cation is characterized by two intramolecularly coordinating amino groups. The two hydroxyethyl groups on N3 and N4 are not coordinated to S2 (O3a' 'S2 $3.804 \AA$, O4 * S2 $4.967 \AA$ ), such that the sulfur atom is essentially three-coordinate. The N-S bonds (2.087(7) $\AA, 2.105(6) \AA$ ) and the N-S-N bond angle $\left(168.2(2)^{\circ}\right)$ in $\mathbf{5}$ are very similar to those in $1\left(2.063(1) \AA, 2.063(1) \AA, 168.54(9)^{\circ}\right)$, as is the dihedral angle between the planes through the $\mathrm{N}_{2} \mathrm{~S}$ and the aryl ring $\left(14.6^{\circ}\right.$ in $\mathbf{5}, 14.3^{\circ}$ in $\left.\mathbf{1}\right)$. The bonding is best described by a N,Nchelated sulfur(II) atom ( $3 \mathrm{c}-4 \mathrm{e}$ bond) bearing two lone pairs and a formal charge of +1 on the basis of the current view of hypercoordinate species [11]. 
Fig. 3. Ball- and stick representation of the structure of the $\left[\mathrm{Ni}_{2} \mathrm{~L}^{3}(\mathrm{Cl})\right]^{2+}$ dication in crystals of $\mathbf{5}(\mathrm{MeOH})_{3}$. Hydrogen atoms have been omitted for clarity except for $\mathrm{OH}$ groups. The intramolecular hydrogen bond between $\mathrm{O} 1$ and $\mathrm{O} 6$ is shown as a dashed line.

Selected bond lengths [Å] and angles [ ]: Ni1-O1 2.048(4), Ni1-O2 2.129(4), Ni1-N1 2.087(6), Ni1-N2 2.207(6), Ni1-S1 2.381(2), Ni1-Cl 2.438(2), Ni2-O5 2.085(5), Ni2-O6 2.053(4), Ni2-N5 2.169(5), Ni2-N6 2.091(6), Ni2-S1 2.422(2), Ni2-Cl 2.452(2), S1-C1 1.760(7), S2-C20 1.749(7), S2-N3 2.087(7), S2-N4 2.105(6); Ni1-Cl-Ni2 88.00(6), Ni1-S1Ni2 90.02(6), N3-S2-N4 168.2(2)

In summary, the use of the perhydroxyethylated ligand $\mathrm{H}_{2} \mathrm{~L}^{2}$ in place of $\mathrm{H}_{2} \mathrm{~L}^{1}$ has enabled the isolation of a unique macrocycle incorporating a cationic aryl sulfenium ion in proximity to a dinickel(II) thiophenolate complex. The presence of the sulfenium ion and the nearby active coordination site at the $\mathrm{Ni}_{2}$ center might enable molecular recognition of zwitterionic 
substrates within macrocyclic cavities. It is also tempting to investigate a possible stabilization of hypercoordinated $\mathrm{S}(\mathrm{IV})$ or $\mathrm{S}(\mathrm{VI})$ species by the $\mathrm{CH}_{2} \mathrm{CH}_{2} \mathrm{OH}$ functions. These topics will be addressed in ongoing studies.

\section{Experimental Part}

General: The ligand $\mathrm{H}_{2} \mathrm{~L}^{2}$ was prepared as described in the literature [7]. The infrared spectra were recorded as $\mathrm{KBr}$ discs using a Bruker VECTOR 22 FT-IR-spectrophotometer. Electronic absorption spectra were recorded on a Jasco V-570 UV/vis/near IR spectrophotometer. ESIFTICR mass spectra were recorded with a Bruker-Daltronics Apex II instrument using dilute MeCN solutions. Caution! Perchlorate salts of transition metal complexes are hazardous and may explode. Only small quantities should be prepared and great care taken.

$\left[\mathrm{Ni}_{2} \mathbf{L}^{3}(\boldsymbol{\mu}-\mathbf{C l})\right]\left[\mathrm{ClO}_{4}\right]_{2}(4)$. To a solution of $\mathrm{H}_{2} \mathrm{~L}^{2} \cdot 6 \mathrm{HCl}(239 \mathrm{mg}, 0.223 \mathrm{mmol})$ in methanol (20 $\mathrm{mL})$ was added with stirring at room temperature a solution of $\left[\mathrm{Ni}\left(\mathrm{H}_{2} \mathrm{O}\right)_{6}\right] \mathrm{Cl}_{2}(106 \mathrm{mg}, 0.446$ mmol) in methanol $(5 \mathrm{~mL})$. A solution of $\mathrm{NEt}_{3}(181 \mathrm{mg}, 1.79 \mathrm{mmol})$ in methanol $(1 \mathrm{~mL})$ was added to give a dark green solution. After stirring for 3 days at ambient temperature in air solid $\mathrm{LiClO}_{4} \cdot 3 \mathrm{H}_{2} \mathrm{O}(358 \mathrm{mg}, 2.23 \mathrm{mmol})$ was added. The solution was concentrated under reduced pressure to ca $25 \%$ of its original volume, and left to stand in an open vessel to give green crystals of the title compound, which were filtered, washed with cold methanol, and dried in vacuum. The crude product was purified by recrystallization from methanol. Yield: $222 \mathrm{mg}(83 \%) . \mathrm{C}_{44} \mathrm{H}_{76} \mathrm{Cl}_{3} \mathrm{~N}_{6} \mathrm{Ni}_{2} \mathrm{O}_{14} \mathrm{~S}_{2}$ (1200.98): calcd. C 44.00, H 6.38, N 7.00, S 5.34; found: C 43.82, H 6.52, N 6.78, S 5.24.

UV/Vis $\left(\mathbf{C H}_{3} \mathbf{C N}\right): \lambda_{\max }(\varepsilon)=646(34), 859(13), 1060 \mathrm{~nm}\left(42 \mathrm{M}^{-1} \mathrm{~cm}^{-1}\right) . \mathbf{I R}\left(\mathrm{KBr}, \mathrm{cm}^{-1}\right): v=$ 3424 s, 2957 m, 2926 m, 2866 m, 2361 vw, 2025 vw, 1631 w, 1454 m, 1398 vw, 1367 w, $1311 \mathrm{vw}, 1262 \mathrm{vw}, 1230 \mathrm{w}, 1108(\mathrm{sh}) \mathrm{vs}, 1087$ (vs, v $\left.{ }_{3}\left[\mathrm{ClO}_{4}^{-}\right]\right), 1004(\mathrm{sh}) \mathrm{w}, 964 \mathrm{vw}, 910 \mathrm{w}$, $878 \mathrm{w}, 763 \mathrm{vw}, 742 \mathrm{vw}, 715 \mathrm{vw}, 677 \mathrm{vw}, 628\left(\mathrm{~m}, \mathrm{v}_{4}\left[\mathrm{ClO}_{4}^{-}\right]\right) . \mathbf{M S}\left(\mathrm{ESI}^{+}, \mathrm{CH}_{3} \mathrm{CN}\right): \mathrm{m} / z$ 
$1097.31\left[\left(\mathrm{M}-\mathrm{ClO}_{4}\right)^{+}, 80 \%\right], 499.17\left[\left(\mathrm{M}-2 \mathrm{ClO}_{4}\right)^{2+}, 100 \%\right]$

$\left[\mathbf{N i}_{2} \mathbf{L}^{3}(\boldsymbol{\mu}-\mathbf{C l})\right]\left[\mathbf{B P h}_{4}\right]_{2}(\mathbf{5})$. A solution of $\mathrm{NaBPh}_{4}(171 \mathrm{mg}, 0.50 \mathrm{mmol})$ in methanol $(2 \mathrm{~mL})$ was added to a solution of $4(120 \mathrm{mg}, 0.10 \mathrm{mmol})$ in methanol $(20 \mathrm{~mL})$ and stirred for $1 \mathrm{~h}$. The green product was filtered, washed with methanol and dried in air to give $136 \mathrm{mg}$ (83\%) of 6 as a green, air-stable, microcrystalline powder. $\mathrm{C}_{92} \mathrm{H}_{115} \mathrm{~B}_{2} \mathrm{ClN}_{6} \mathrm{Ni}_{2} \mathrm{O}_{6} \mathrm{~S}_{2}$ (1639.53): calcd. C 67.40, H 7.07, N 5.13, S 3.91; found: C 67.21, H 7.28, N 5.28, S 4.02.

UV/Vis $\left(\mathrm{CH}_{3} \mathrm{CN}\right): \lambda_{\max }(\varepsilon)=651(36), 863(14), 1059 \mathrm{~nm}\left(48 \mathrm{M}^{-1} \mathrm{~cm}^{-1}\right) . \mathbf{I R}\left(\mathrm{KBr}, \mathrm{cm}^{-1}\right): v=$ 3515 w, 3055 w, 2965 w, 2901 w, 1947 vw, 1882 w, 1820 vw, 1611 w, 1580 w, 1478 w, 1455 w, 1427 w, 1394 w, 1367 w, 1349 w, 1315 w, 1265 w, 1229 w, 1181 vw, 1155 w, 1133 w, 1065 m, 1030 w, 1003 w, 966 w, 908 w, 882 w, 872 w, 847 w, 805 w, 755 w, 734 [s, v(BPh4 )], $704\left[\mathrm{vs}, v\left(\mathrm{BPh}_{4}{ }^{-}\right)\right], 625 \mathrm{w}, 611 \mathrm{~m} . \mathbf{M S}\left(\mathrm{ESI}^{+}, \mathrm{MeOH}\right): \mathrm{m} / z 1317.52\left[\left(\mathrm{M}-\mathrm{BPh}_{4}\right)^{+}, 60 \%\right]$, $499.17\left[\left(\mathrm{M}-2 \mathrm{ClO}_{4}\right)^{2+}, 100 \%\right]$.

Single crystals suitable for an X-ray structure analysis were grown by slow evaporation of an methanol/acetonitrile (1:2) solution of complex salt 5. The data set was collected at 213(2) K using a STOE IPDS-2T diffractometer and graphite monochromated Mo-K $\alpha$ radiation (0.71073 $\AA$ ). The intensity data were processed with the program STOE X-AREA. The structure was solved by Direct Methods [12] and refined by full-matrix least-squares on the basis of all data against $F^{2}$ using SHELXL-97 [13]. PLATON was used to search for higher symmetry [14]. Drawings were produced with Ortep-3 for Windows [15]. Unless otherwise specified the $\mathrm{H}$ atoms were placed at calculated positions and refined as riding atoms with isotropic displacement parameters. All non-hydrogen atoms were refined anisotropically.

Crystal data for 5·3MeOH: $\mathrm{C}_{95} \mathrm{H}_{127} \mathrm{~B}_{2} \mathrm{ClN}_{6} \mathrm{Ni}_{2} \mathrm{O}_{9} \mathrm{~S}_{2}, M_{\mathrm{r}}=1735.64$, monoclinic, space group $P 2_{1} / c, a=21.939(2) \AA, b=18.348(1) \AA, c=22.962(2) \AA, \beta=96.66(1), V=9181(1) \AA^{3}, Z=$ 
4, $\rho_{\text {calcd }}=1.256 \mathrm{~g} \mathrm{~cm}^{-3} ; \mu\left(\mathrm{Mo}_{\mathrm{Ka}}\right)=0.544 \mathrm{~mm}^{-1}(\lambda=0.71073 \AA) ; 61360$ reflections measured, 15146 unique, 7410 with $I>2 \sigma(I)$, refinement converged to $R_{1}=0.0848, w R_{1}=0.2276(I$ $2 \sigma(I)), \mathrm{R}_{2}=0.1384, w R_{2}=0.2494$ (all data); 931 parameters. The poor quality of the X-ray data is a consequence of a disordered $\mathrm{BPh}_{4}{ }^{-}$ion, a disordered $t \mathrm{Bu}$ group, and a disordered $\mathrm{CH}_{2} \mathrm{CH}_{2} \mathrm{OH}$ group. The disorders were modeled by split atom models using SADI instructions implemented in the SHELXTL software package. The hydroxyethyl OH hydrogen atoms were located from final difference Fourier maps but their positions were refined as riding atoms with isotropic displacement parameters, min./max. residual electron density $=+1.566 /-3.396 \mathrm{e} / \AA^{3}$.

CCDC-762675 contains the supplementary crystallographic data for this paper. These data can be obtained free of charge from The Cambridge Crystallographic Data Centre via $\underline{\text { www.ccdc.cam.ac.uk/data_request/cif. }}$

Acknowledgements. We are grateful to the DFG for financial support of this work. We also thank Prof. H. Krautscheid for providing facilities for X-ray crystallographic analyses.

[1] Representative Examples (a) N. Furukawa, K. Kobayashi, S. Sato, J. Organomet. Chem. 2000, 611, 116-126. (b) N. Furukawa, S. Sato, Topics Current Chemistry, 1999, 205, 89-129. (c) S. Sato, O. Takahashi, N. Furukawa, Coord. Chem. Rev. 1998, 176, $483-$ 514. (d) C. Deleanu, J. E. Drake, M. B. Hursthouse, M. Kulcsar, M. E. Light, A. Silvestru, Appl. Organometal. Chem. 2002, 16, 727-731. (e) R. Kaur, H. B. Singh, R. P. Patel, J. Chem. Soc., Dalton Trans. 1996, 2719-2726. (f) A. Panda, C. Mugesh, H.-B. Singh, R. J. Butcher Organometallics 1999, 18, 1986-1993. (g) C. D. Martin, M. C. Jennings, M. J. Ferguson, P. J. Ragogna, Angew. Chem. 2009, 121, 2244 - 2247; Angew. Chem. Int. Ed. 2009, 48, 2210-2213. 
[2] H. Fujihara, H. Mima, N. Furukawa, N. J. Am. Chem. Soc. 1995, 117, 10153-10154.

[3] K. Kobayashi, S. Sato, E. Horn, N. Furukawa, Angew. Chem. 2000, 112, 1374-1376, Angew. Chem. Int. Ed. 2000, 39, 1318-1320.

[4] Kobayashi, K.; Sato, S.; Horn, E.; Furukawa, Tetrahedron Lett. 1998, 39, 2593-2596.

[5] V. Lozan, C. Loose, J. Kortus, B. Kersting, Coord. Chem. Rev. 2009, 253, 2244-2260.

[6] B. Kersting, Angew. Chem. 2001, 113, 4110-4112; Angew. Chem. Int. Ed. 2001, 40, 3987-3990.

[7] M. Gressenbuch, B. Kersting, Dalton Trans. 2009, 5281-5283.

[8] Complex 4 is not produced in the absence of air.

[9] S. Brooker, C.B. Caygill, P. D. Croucher, T. C. Davidson, D. L. J. Clive, S. R. Magnuson, S. P. Cramer, C. L. Raston, J. Chem. Soc., Dalton Trans. 2000, 3113-3121.

[10] F. Meyer, Eur. J. Inorg. Chem. 2006, 3789-3800.

[11] D. Stalke, H. Ott, Nachr. Chem. 2008, 56, 131-135.

[12] G. M. Sheldrick, Acta Crystallogr. 1990, A46, 467-473.

[13] G. M. Sheldrick, SHELXL-97, Computer program for crystal structure refinement, University of Göttingen, Göttingen, Germany, 1997.

[14] Spek, A. L. PLATON - A Multipurpose Crystallographic Tool; Utrecht University, Utrecht, The Netherlands, 2000.

[15] L. J. Farrugia, J. Appl. Crystallogr. 1997, 30, 565. 


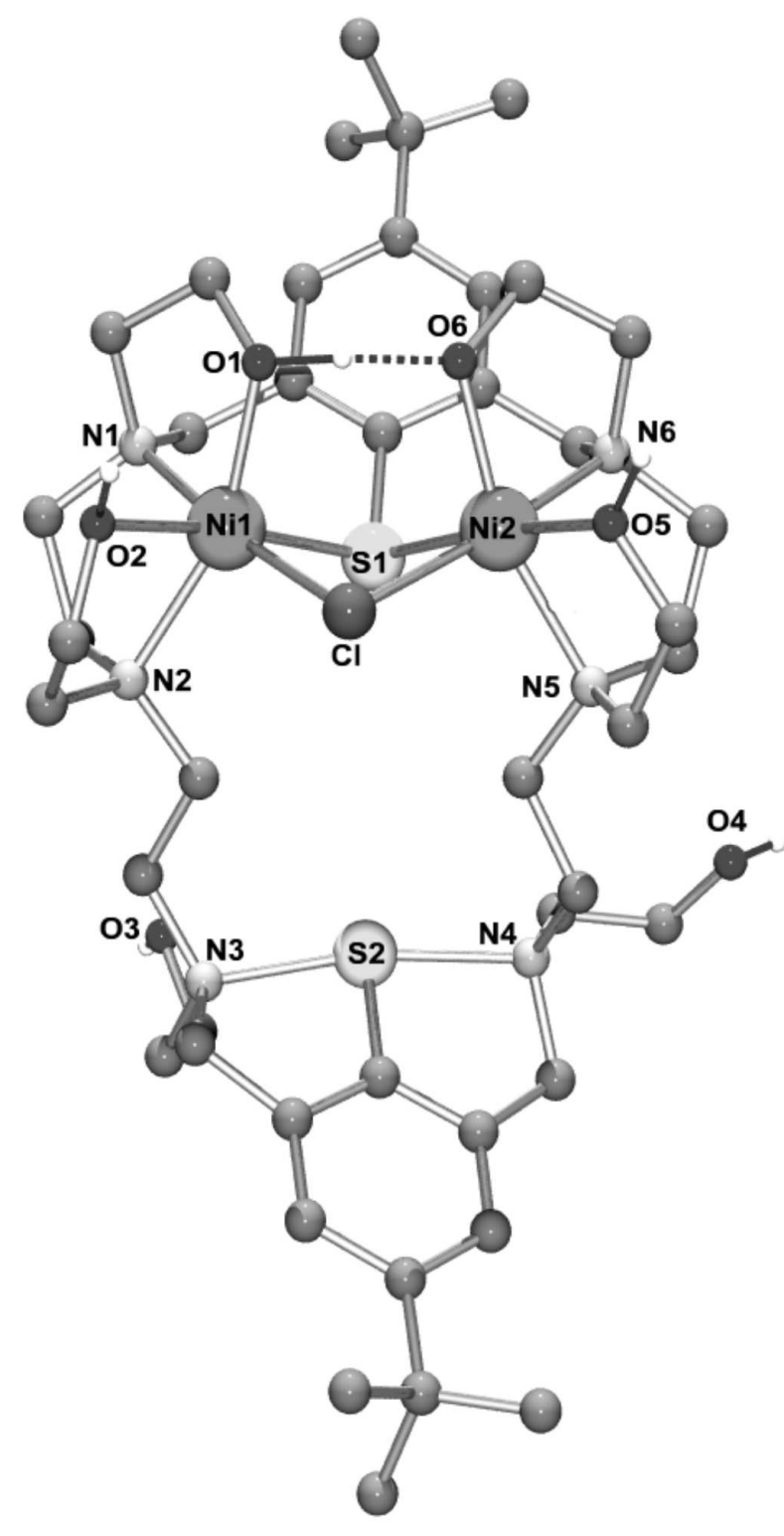

Ball and stick ....

$304 \times 541 \mathrm{~mm}$ (96 x 96 DPI)

Wiley-VCH 